\title{
Genotypes of Staphylococcus aureus: On-farm epidemiology and the consequences for prevention of intramammary infections
}

\author{
A. Leuenberger, ${ }^{1}$ C. Sartori, ${ }^{1,2}$ R. Boss, ${ }^{1}$ G. Resch, ${ }^{3}$ F. Oechslin, ${ }^{3}$ A. Steiner, ${ }^{2}$ P. Moreillon, ${ }^{3}$ and H. U. Graber ${ }^{1 *}$ \\ ${ }^{1}$ Agroscope, Institute for Food Science (IFS), 3003 Berne, Switzerland \\ ${ }^{2}$ Clinic for Ruminants, Department of Clinical Veterinary Medicine, Vetsuisse Faculty, University of Berne, 3012 Berne, Switzerland \\ ${ }^{3}$ Department of Fundamental Microbiology, University of Lausanne, 1015 Lausanne, Switzerland
}

\section{ABSTRACT}

Staphylococcus aureus is a highly contagious mastitiscausing pathogen infecting dairy cattle worldwide. Previous studies have shown the presence of different genotypes (GT) on farms. In Switzerland, Staph. aureus genotype B (GTB) is contagious, whereas GTC and other genotypes cause sporadic, noncontagious mastitis. In this study, we evaluated the epidemiological properties of Staph. aureus, together with its genotypes and spa types, on Swiss dairy farms. A total of 21 dairy farms were sampled throughout Switzerland; 10 farms were positive for the contagious Staph. aureus GTB and 11 farms were negative for GTB. Samples were taken from milk, body surfaces of dairy cattle and other animals, milkers, milking equipment, and environmental sites (e.g., parlor, washing room, stall floor, manger, and bedding). The epidemiology of Staph. aureus depended markedly on the genotype. Staphylococcus aureus GTB was associated with mammary gland, intramammary infections (IMI), and milking clusters, whereas GTC and other genotypes were related to cow and other animal surfaces and occasionally to environment. Genotype $\mathrm{C}$ was by far the most common subtype in cattle and was found on GTB-negative and GTB-positive farms. Each farm had a predominant genotype, such as GTB, GTC, GTA, or GTF, but a few farms were almost free from Staph. aureus. The genotypes and spa types of Staph. aureus detected in the noses of milkers clearly differed from those found in dairy cattle, other animals, milking equipment, and the environment. Exceptions were GTS (spa type t034) and GTF (t899), which crossed the species barrier. In most cases, however, the species barrier was maintained because Staph. aureus is adapted to a particular host and even to particular body sites. As biological properties differ among the genotypes, new guidelines to prevent IMI caused by different genotypes were established: classical measures to

Received June 26, 2018.

Accepted December 9, 2018.

*Corresponding author: hansulrich.graber@agroscope.admin.ch prevent IMI caused by contagious pathogens still hold for GTB but not for Staph. aureus genotypes that are opportunistic colonizers of bovine skin (e.g., GTC and GTA). For those genotypes, protection of the skin from minor lesions and wounds, particularly on the hocks, is essential.

Key words: Staphylococcus aureus, subtypes, milk, environment

\section{INTRODUCTION}

Staphylococcus aureus causes contagious and mostly chronic mastitis in cattle worldwide (Barkema et al., 2006) as well as large economic losses due to reduced milk production, discarded milk, and increased treatment costs (Halasa et al., 2007; Heiniger et al., 2014). Studies by Fournier et al. (2008) and Graber et al. (2009) using 16S-23S ribosomal spacer PCR (RS-PCR) identified various bovine genotypes of Staph. aureus with different virulence and pathogenicity factors. Mainly Staph. aureus genotype B (GTB) and genotype C (GTC) were found in Swiss dairy herds (80\%), whereas other Staph. aureus genotypes (GTOG) were rarely present (Fournier et al., 2008). Studies by Cosandey et al. (2016) and Boss et al. (2016) confirmed the Swiss results at the European level: Staph. aureus GTB, GTC, and GTR were the most prominent genotypes, followed by GTF, GTI, and a set of 41 genotypes with rare occurrence. Interestingly, Staph. aureus GTB was restricted to central Europe, whereas GTC and GTR were present all over Europe (Cosandey et al., 2016). Furthermore, GTB is of primary importance on dairy farms because it is related to high contagiousness and pathogenicity (Fournier et al., 2008; Graber et al., 2009; van den Borne et al., 2017), causing herd problems with a cow-level mastitis prevalence of up to $87 \%$. A representative study using a stratified random selection of 223 Swiss dairy herds showed that $10.3 \%$ of these herds were infected with Staph. aureus GTB (Cosandey et al., 2016); in the study by Berchtold et al. (2014), 16\% of Swiss dairy herds $(\mathrm{n}=100)$ were GTB-positive. That Staph. aureus GTB can also enter the milk food chain 
(raw milk cheese) and cause enterotoxin intoxication in humans was demonstrated by Hummerjohann et al. (2014). Those authors found that GTB was the most abundant genotype in raw milk cheese. In contrast to GTB, Staph. aureus GTC and GTOG cause sporadic and noncontagious IMI and are, therefore, less problematic (Fournier et al., 2008; Graber et al., 2009).

Genotyping by RS-PCR, as used by Fournier et al. (2008) and Cosandey et al. (2016), allows subtyping of Staph. aureus in a robust, reproducible, and costefficient way. In addition, this method is characterized by high resolution and is associated with the virulence gene pattern of bovine strains (Fournier et al., 2008; Graber et al., 2009; Cremonesi et al., 2015; Cosandey et al., 2016). Besides RS-PCR, other subtyping methods have been used to further characterize staphylococcal IMI isolates such as spa typing (e.g., Boss et al., 2016; Lundberg et al., 2016), multilocus sequence typing (e.g., Hata et al., 2010; Boss et al., 2016), pulsed-field gel electrophoresis (e.g., Capurro et al., 2010; Cremonesi et al., 2015), and amplified fragment length polymorphism (Sakwinska et al., 2011). Their suitability for large clinical investigations, however, is mainly limited by low throughput or high cost. On the other hand, many of these methods rely on standard laboratory equipment, whereas RS-PCR requires a high-resolution electrophoresis system (Fournier et al., 2008). In spite of the considerable laboratory effort required (Harmsen et al., 2003), spa typing is widely used to subtype human staphylococcal strains and has generated much clinical and epidemiological data (http://www.spaserver.ridom .de/; Grundmann et al., 2010) on these subtypes. To compare animal strains with human strains of Staph. aureus, spa typing is, therefore, inevitable (Boss et al., 2016); spa typing is based on DNA sequencing of the variable spacer region of the staphylococcal spa gene and inferring a pattern of repeats (Harmsen et al., 2003).

The aim of the present study was to evaluate the on-farm epidemiology of Staph. aureus GTB and other genotypes and to establish guidelines to prevent IMI caused by different genotypes. We analyzed samples from milk, different body sites of dairy cattle and other animals, the environment, milking equipment, and milkers.

\section{MATERIALS AND METHODS}

\section{Herd Selection}

Farms were recruited with the support of the official laboratory for milk quality testing in Switzerland (Suisselab, Zollikofen, Switzerland), which sent an informative letter with a short description of our study to all of their farmers who had observed cows with IMI caused by Staph. aureus during the last year. Interested farmers were invited to contact us for further information. In addition, practicing veterinarians were asked to report farms on which Staph. aureus mastitis had been detected during the last year. A bulk tank milk (BTM) sample was taken once from each of 42 interested farms and tested for Staph. aureus GTB. Lactating cows not milked into the bulk tank were separately sampled and analyzed. Testing for Staph. aureus GTB was performed according to Boss et al. (2011), with the modification of Voelk et al. (2014). This quantitative real-time PCR (qPCR) method is highly specific and sensitive for GTB (Boss et al., 2011): 1 GTB-shedding cow among 138 cows can be detected in BTM (Boss et al., 2011). Herds were grouped depending on the BTM GTB results: if BTM was positive for GTB, the herd was selected for the case group and if negative for the control group.

Out of the analyzed farms, 10 GTB-positive dairy farms (case farms) and 11 GTB-negative farms (control farms) were randomly selected. All farms included in the present study were spread throughout Switzerland and representative of Swiss farms in terms of breed, size, and milking and housing systems (Table 1). Cows were either kept in tiestalls ( 4 case and 6 control farms) or in freestalls ( 6 case and 5 control farms).

\section{Sample Collection}

The recruited farms were visited and the animals and environment were sampled once. On the farm, herd management was evaluated using a questionnaire collecting data about milk production; type of stall (freestall, tiestall); cleanliness of animals, stall, parlor and bedding; type of bedding (straw, chopped straw, straw-manure, sawdust, compost, natural wool, rubber mat); milking hygiene and equipment; milking procedure; usage of gloves for milking (yes/no); and postmilking teat dipping (yes/no).

Sampling on animals was done under accordance of the Cantonal Animal Experiment Commission, issued by the Canton of Berne, Switzerland (LANAT; Office of Agriculture and Nature). Ethical clearance to sample humans was obtained from the Ethical Committee of the University of Lausanne, Switzerland.

On each farm, the same highly standardized sampling procedure was performed: (1) aseptic collecting of milk from every lactating quarter; (2) swabbing of all cow quarters; (3) swabbing of all cow hocks; (4) swabbing of the body surface (perineum) of all cows; (5) swabbing of all milkers (consenting); (6) swabbing of all milking clusters before and after milking (see below for details). In addition, on each farm, the basin for wash- 
ing the milking equipment, the floor of the corresponding room, the floor of the milking parlor, and the stall floor(s), manger(s), and bedding were always sampled (see below for details). Other environmental sites (wall of washing room and parlor, utensils used in the stall, sites frequently touched by cows, inner side of drinking basin, dummies for feeding calves, flies) were sampled when present. The same was also true for the sampling of the cows' outer nostrils (first 2 to $3 \mathrm{~cm}$ of the nasal duct) and body surfaces of animals other than cows.

\section{Environmental Sampling}

Environmental samples were collected first. Sample collectors wore shoe protectors and gloves to prevent contamination from the collectors. Sampling was performed using sterile dental cotton rolls (DCR; Coltène/Whaledent AG, Altstaetten, Switzerland) moistened with $0.9 \% \mathrm{NaCl}$. At the beginning, floor and wall samples were taken from the milking parlor (only in freestalls) followed by samples of the washroom floor and wall, stall floor(s), and manger(s). Four separate DCR were used to swab each of these locations and surfaces, with each DCR sampling a surface of approximately $1 \mathrm{~m}^{2}$; one additional DCR was used to swab the inner side of the washbasin (approximately $1 \mathrm{~m}^{2}$ ).
Scratching brushes (if available), door edges, and other frequently touched surfaces, including the inner side of drinking basins, were each swabbed with a separate DCR. If available, dummies used for calf feeding were each swabbed on the inner side before use.

For each stall of a farm, the lying places of 1 to 2 cows were sampled as follows: at the rear one-third of the surface, about $1 \mathrm{~m}^{2}$ of the bedding material was collected with sterile gloves and mixed; then, a handful was placed into a sterile plastic bag.

On each farm, every milking cluster was sampled twice. To do so, the inner surfaces of all 4 liners of a cluster were swabbed before milking using, for each cluster, 1 microbiology swab soaked in Amies transport medium (ASW, Transwab Amies; Medical Wire and Equipment, Corsham, UK). The identical procedure of liner swabbing was then repeated after milking.

\section{Animal Sampling}

Different surfaces on each lactating cow of a herd were swabbed using microbiology ASW. In particular, samples were taken from lateral hock skin (both legs), perineum, outer nostrils (the first 2 to $3 \mathrm{~cm}$ of the nasal duct) and, if present, from wounds. For each location, a single ASW was used. In the case of hock skin and

Table 1. Descriptive overview about the case and control farms

\begin{tabular}{|c|c|c|c|c|c|c|c|}
\hline Farms & Breed & $\begin{array}{l}\text { Cows } \\
(\mathrm{n})\end{array}$ & Housing & Bedding & $\begin{array}{l}\text { Milking } \\
\text { system }\end{array}$ & Gloves & $\begin{array}{l}\text { Postmilking } \\
\text { teat dipping }\end{array}$ \\
\hline \multicolumn{8}{|c|}{ Case farms } \\
\hline 1 & Brown-Swiss & 18 & Freestall & Straw/sheep wool & Milking parlor & No & Yes \\
\hline 2 & Holstein & 31 & Freestall & Straw-manure & Milking parlor & No & No \\
\hline 3 & Brown-Swiss & 30 & Tiestall & Rubber mat/sawdust & $\begin{array}{l}\text { Pipe and bucket } \\
\text { milking }\end{array}$ & No & Yes \\
\hline 4 & Brown-Swiss & 21 & Tiestall & Rubber mat/chopped straw & Pipe milking & Yes & Yes \\
\hline 5 & Original Brown & 12 & Freestall & Straw-manure & Milking parlor & No & No \\
\hline 6 & Simmental & 21 & Tiestall & Rubber mat/chopped straw & Pipe milking & Yes & Yes \\
\hline 7 & $\begin{array}{l}\text { Brown-Swiss/ } \\
\text { Holstein }\end{array}$ & 50 & Freestall & Rubber mat/chopped straw & Robotic system & No & Yes \\
\hline 8 & Brown-Swiss & 19 & Freestall & Straw box & Milking parlor & Yes & Yes \\
\hline 9 & Montbéliarde & 102 & Freestall & Compost & $\begin{array}{l}\text { Milking } \\
\text { roundabout }\end{array}$ & Yes & Yes \\
\hline 10 & Brown-Swiss & 27 & Tiestall & Rubber mat & Pipe milking & No & Yes \\
\hline \multicolumn{8}{|c|}{ Control farms } \\
\hline 11 & Red-Holstein & 32 & Tiestall & Straw & Pipe milking & No & No \\
\hline 12 & Swiss-Fleckvieh & 27 & Freestall & Straw-manure & Milking parlor & No & Yes \\
\hline 13 & Red-Holstein & 29 & Tiestall & Rubber mat/straw & Pipe milking & Yes & Yes \\
\hline 14 & Swiss-Fleckvieh & 15 & Freestall & Straw-manure & Milking parlor & No & No \\
\hline 15 & Red-Holstein & 31 & Tiestall & Rubber mat & Pipe milking & No & Yes \\
\hline 16 & Red Holstein & 37 & Freestall & Chopped straw & Milking parlor & Yes & Yes \\
\hline 17 & Holstein & 32 & Freestall & Straw-manure & Milking parlor & Yes & Yes \\
\hline 18 & Red-Holstein & 24 & Freestall & Straw-manure & Milking parlor & No & Yes \\
\hline 19 & Swiss-Fleckvieh & 19 & Tiestall & Rubber mat & Pipe milking & No & Yes \\
\hline 20 & Red Holstein & 27 & Tiestall & Rubber mat/straw & Bucket milking & No & No \\
\hline \multirow[t]{2}{*}{21} & Brown-Swiss & 27 & Tiestall & Rubber mat & Pipe milking & Yes & Yes \\
\hline & $\begin{array}{l}\text { Total cows } \\
\text { (lactating) }\end{array}$ & $631(616)$ & & & & & \\
\hline
\end{tabular}


perineum, the sampling surface ranged from 50 to 70 $\mathrm{cm}^{2}$. For heifers (from 1.5 to $2.5 \mathrm{yr}$ of age), the sampling sites were identical to those of cows except that the whole juvenile udder was swabbed. Preweaning calves were sampled on the outer nostrils and on the umbilicus, using 1 ASW each. Depending on the size of the farm and the availability of the animals, 1 to 3 heifers and calves were swabbed, respectively. Other on-farm animals, including cats, dogs, goats, horses, and pigs, were sampled on the nostrils using $1 \mathrm{ASW}$ each. If present (rare), live flies in the barn were captured with new one-way gloves and put into sterile tubes.

Sampling of milk and teat skin was performed during either the morning or evening milking, including from all lactating cows. The udder was visually inspected and abnormalities such as warts or injuries were noted. Gloves were worn during the sampling. The skin of all 4 teats of a cow was completely swabbed using $1 \mathrm{ASW}$ for all. Afterward, a short primary cleaning and premilking were performed followed by the California Mastitis Test. Subsequently, the orifice and skin of each teat were thoroughly cleaned and disinfected using gauze pledgets soaked with $70 \%$ ethanol, and single quarter milk samples were milked in sterile plastic tubes. At the end of milking, BTM was collected following the guidelines of the National Mastitis Council (NMC, 1999).

\section{Sampling of Milkers}

The milkers (all male) were sampled before and after milking; all participated voluntarily. Samples were taken from the surface of clothes used for milking (front side and sleeves), palm skin of both hands, and the inner side of both nostrils. For each location, a separate ASW was used. Swabbing was performed by the sampler except for the nose sampling, which was carried out by the milker.

All samples were placed into a plastic box and transported in portable cooler $\left(4^{\circ} \mathrm{C}\right)$ to the laboratory, where the swabs and bedding samples were stored at $4^{\circ} \mathrm{C}$ and processed within the next $5 \mathrm{~d}$. Milk samples were frozen and stored at $-20^{\circ} \mathrm{C}$ until further use.

\section{Processing of Swab Samples}

Staphylococci adhered to the swabs were grown in Chapman broth (CB) containing $10 \mathrm{~g} / \mathrm{L}$ casein peptone (Merck, Berne, Switzerland), $1 \mathrm{~g} / \mathrm{L}$ meat extract (Oxoid AG, Basel, Switzerland), 75 g/L NaCl (Merck), and $10 \mathrm{~g} / \mathrm{L}$ D-mannitol (Fluka, Buchs, Switzerland). Each ASW was added to a glass tube containing 4.5 $\mathrm{mL}$ of CB. Each DCR was placed into a $100-\mathrm{mL}$ glass bottle filled with $40 \mathrm{~mL}$ of CB. Bedding material (10 to $15 \mathrm{~g}$ ) was added to a sterile plastic bag, diluted
1:10 with $\mathrm{CB}$, and manually kneaded for $30 \mathrm{~s}$. Tubes, bottles, and bags were then incubated at $37^{\circ} \mathrm{C}$ for $18 \mathrm{~h}$.

Afterward, to reduce later workload, pools of the cultures (except for bedding material) were prepared and tested for the presence of Staph. aureus by qPCR (see below): for each cow, ASW cultures of each sampled site were pooled by adding $500 \mu \mathrm{L}$ of each culture into a single tube. Separate pools were prepared from all cultures of swabs collected from all heifers, calves, other animals, humans, milking equipment, pen, or milking parlor, including washroom. Because DCR cultures normally contained hair, dirt, or other large particles, they were filtered through sterile paper filter (Schleicher and Schuell, Feldbach, Switzerland) before pooling. All types of pools were then incubated at $37^{\circ} \mathrm{C}$ for $18 \mathrm{~h}$.

\section{DNA Extraction of Pools and qPCR Analysis}

After incubation, DNA of each pool described above was extracted using $1 \mathrm{~mL}$ of pooled culture together with the Mericon DNA Bacteria plus Kit (Qiagen AG, Hombrechtikon, Switzerland) as described by Syring et al. (2012). The DNA was eluted in $100 \mu \mathrm{L}$ of $10 \mathrm{mM}$ Tris $/ \mathrm{HCl}$ ( $\mathrm{pH}=8.5$; from the kit) and was stored at $-20^{\circ} \mathrm{C}$ until further use as a template for qPCR.

We applied qPCR of the nuc gene to test the pools for the presence of Staph. aureus. The assay is highly specific for Staph. aureus (Graber et al., 2007; Boss et al., 2011) and was performed as described previously (Boss et al., 2011). In the current study, results were considered positive for Staph. aureus if the cycle threshold $\left(\mathrm{C}_{\mathrm{T}}\right)$ value was $<30$ cycles.

For each pool with a positive nuc qPCR result, 30 $\mu \mathrm{L}$ of each original culture that contributed to the corresponding pool was spread on a CHROM plate (CHROMagar, Paris, France). The same volume was plated for each sample of bedding culture. CHROMagar plates were used because this medium is highly specific for Staph. aureus (Graber et al., 2013). The plates were then incubated at $37^{\circ} \mathrm{C}$ for $24 \mathrm{~h}$. On each plate, 3 mauve colonies (presumptive for Staph. aureus) or as many as possible were picked and each resuspended in a separate $1.5-\mathrm{mL}$ tube containing $100 \mu \mathrm{L}$ of TEL buffer (10 $\mathrm{m} M$ Tris/HCl, $10 \mathrm{~m} M$ EDTA; $\mathrm{pH} 8.5$ ). Afterward, the tubes were incubated at $95^{\circ} \mathrm{C}$ for $10 \mathrm{~min}$ and immediately placed on ice. The resulting lysates were then diluted 1:100 in $\mathrm{H}_{2} \mathrm{O}$ and stored at $-20^{\circ} \mathrm{C}$ until used as DNA templates for the various PCR.

\section{Processing of Milk Samples}

Phenotypic Analyses. Milk samples were thawed at $37^{\circ} \mathrm{C}$ for $10 \mathrm{~min}$ in a water bath and gently mixed to obtain a homogeneous suspension. Afterward, $25 \mu \mathrm{L}$ 
of milk from each quarter of a cow was placed, using a pipette, in the middle of a CHROM plate on a turntable and scattered using a sterile triangular glass spatula. The plates were incubated at $37^{\circ} \mathrm{C}$ for $24 \mathrm{~h}$. From cows with a positive Staph. aureus result, $30 \mu \mathrm{L}$ of milk from each quarter was then streaked out on a blood agar plate containing $5 \%$ sheep blood (bioMérieux, Geneva, Switzerland) and incubated at $37^{\circ} \mathrm{C}$ for $24 \mathrm{~h}$ and $48 \mathrm{~h}$. This analysis using $30 \mu \mathrm{L}$ of milk was performed to obtain an overview of all bacteria in the sample and to ensure that the positive Staph. aureus result was not due to contamination. The blood agar plates were evaluated according to the NMC (1999) guidelines in terms of morphology, hemolysis, catalase activity, mobility, and Gram stain. Contamination was defined as the presence of $>3$ morphologically distinct colonies per plate. These milk samples were excluded from further analyses.

DNA Extraction. On each CHROM plate, 3 (or as many as possible) mauve colonies presumptive for Staph. aureus were picked, and each was resuspended in a separate $1.5-\mathrm{mL}$ tube containing $100 \mu \mathrm{L}$ of TEL buffer and further processed as described above.

\section{Identification of Staph. aureus by PCR and Genotyping}

We used melting curve PCR to definitely identify the mauve colonies that were picked from the swabs and the milk samples as Staph. aureus. To do so, the corresponding DNAs were analyzed by melting curve PCR for the nuc gene, as described by Syring et al. (2012). Isolates with a single melting peak identical to the Staph. aureus positive control were considered to be Staph. aureus. These isolates were then genotyped by RS-PCR together with a miniaturized electrophoresis system (Agilent Technologies, Santa Clara, CA) as described by Fournier et al. (2008).

As a backup, each genotyped isolate was regrown on blood agar plates. Then, a loopful of colonies was collected, resuspended in $500 \mu \mathrm{L}$ of sterile skim milk, and frozen at $-20^{\circ} \mathrm{C}$.

\section{spa Typing}

Analysis of the spa type was performed as described by Boss et al. (2016). In brief, the variable $\mathrm{X}$ region of the spa gene was amplified in a total volume of $25 \mu \mathrm{L}$ containing $300 \mathrm{nmol}$ of each spa primer (Boss et al., 2016), $12.5 \mu \mathrm{L}$ of HotStarTaq master Mix (Qiagen), and $2.5 \mu \mathrm{L}$ of DNA diluted 1:20 in $\mathrm{H}_{2} \mathrm{O}$. The reactions were run in a T-Professional thermal cycler (Biome- tra, Göttingen, Germany). Cycling included an initial denaturation step at $95^{\circ} \mathrm{C}$ for $15 \mathrm{~min}$ followed by 37 cycles of denaturation at $94^{\circ} \mathrm{C}$ for $60 \mathrm{~s}$, annealing at $60^{\circ} \mathrm{C}$ for $60 \mathrm{~s}$, and extension at $72^{\circ} \mathrm{C}$ for $60 \mathrm{~s}$. The PCR was terminated by a single extension step at $72^{\circ} \mathrm{C}$ for $10 \mathrm{~min}$. The PCR products were sent to a commercial sequencing center (Microsynth AG, Balgach, Switzerland) for clean up and DNA sequencing. The obtained sequences were then evaluated for the corresponding spa type (t) using the spa typing website (http://www .spaserver.ridom.de/; Harmsen et al., 2003).

\section{Statistics}

Data were expressed as frequencies and percentages. Contingency tables including $2 \times 2$ and $\mathrm{k} \times \mathrm{m}$ tables were evaluated by Fisher's exact test and a generalized version of the test, respectively. The $\mathrm{k} \times \mathrm{m}$ tables were used to analyze an overall association among genotypes and spa types and the tested farms, among genotypes and spa types and animal sites, and among genotypes and spa types found on humans and on all other sites that were tested in the present study. The $\mathrm{k} \times \mathrm{m}$ tables were further applied to study associations between a subset of data, whereas $2 \times 2$ contingency tables were used to study binary questions; for example, whether an association existed between the presence of Staph. aureus GTC and the type of housing (tiestalls vs. freestalls).

Data evaluation and the statistical tests were all performed using Systat 13.1 software (Systat Software, San Jose, CA). In case of multiple testing, the $P$-values were adjusted according to Holm (1979). A value of $P$ $<0.05$ was considered significant.

\section{RESULTS}

A total of 21 Swiss dairy farms were tested (Table 1). On 11 farms, cows were held in freestalls, and on 10 farms, cows were held in tiestalls. Tiestalls were exclusively equipped with rubber mats, most often combined with chopped straw or sawdust (Table 1). The bedding material in freestalls was mostly straw-manure and straw and rarely compost or straw together with sheep wool (Table 1). Postmilking teat dipping was performed on 8 of 10 case farms and on 8 of 11 control farms, respectively $(P=1.0)$. Milkers wore gloves on 4 case farms and on 4 control farms, respectively $(P=$ 1.0; Table 1).

Overall, 5,547 samples comprising 2,461 milk samples and 3,086 swabs were analyzed. Staphylococcus aureus was detected and genotyped by RS-PCR in 386 samples 
(7.0\%). Of these, $158(40.9 \%)$ were positive for GTC, $125(33.4 \%)$ were positive for GTB, and $103(26.7 \%)$ were positive for GTOG.

\section{Distribution of Genotypes and spa Types on Farms}

A clear association $(P<0.001)$ was observed among genotypes and the tested farms, excluding data from human strains of Staph. aureus (Table 2). All GTBpositive isolates $(100 \%)$ were detected on the case farms (Table 3), and none were found on the control farms ( $P$ $<0.001$ ). Genotype $\mathrm{C}$ was found on both farm types but more often on control farms than on case farms $(P=0.019)$, whereas GTOG ("other genotypes") was observed on both farm types at very similar relative frequencies $(P=0.184)$. Three control farms (farms 12 , $16,17)$ were almost free from Staph. aureus.

Every case farm was characterized by the presence of a single (farms $1,2,4,6,8,10$ ) or a main (farms 3,5 , 7,9) spa type that was associated with Staph. aureus GTB (Table 2). In total, $87 \%$ of all GTB isolates were positive for t2953, $5 \%$ were positive for t2915 (farm 10), and $4 \%$ were positive for t3802 (farm 2), respectively. In $4 \%$, the spa type remained unknown. The case farms were further characterized by the presence of other genotypes, particularly of GTC (always t529), but others (GTA, GTF, GTI, GTP, GTR, and GTS; human isolates excluded) were sporadically detected (Table 2). Genotype $\mathrm{C}$ was largely associated with body sites of cattle such as teat surfaces, hocks, and other body sites, including wounds (Table 2). In 4 cases, GTC was involved in IMI. If GTC was isolated from an IMI or from cow surfaces (particularly hocks and teat surfaces), this genotype was repeatedly observed in the milking clusters (inner surface of liners) after milking (Table 2). A particular situation was observed on farm 10 where, in addition to GTB, Staph. aureus GTS (always t034) was isolated from the noses of pigs but also from the nose of the milker, from milk of IMI, and from a milking cluster (Table 2).

Considering the control farms (Table 2), on 3 farms (farms 12, 16, 17) Staph. aureus was very rarely observed (2 to 3 isolates per farm). For the remaining farms, each was characterized by a predominant genotype and spa type, mostly GTC (always t529). On these farms, Staph. aureus GTC was mainly associated with the body sites of cattle but was also present in the environment (Table 2). If GTC was observed on cows (particularly hocks and teat surfaces), this genotype could also be observed in the milking clusters after milking (Table 2). Other predominant genotypes were GTA (farm 18), GTF (farm 14), and GTR (farm 20). Genotype A (always t529) was present on cows (particularly hocks and teat surfaces) and could be observed in the milking clusters (Table 2). For Staph. aureus GTF (farm 14), the isolates were always positive for t164 and could be detected in milk with IMI, teat surfaces, hocks, on heifers, on a cat, in the milking equipment, but also in the environment, particularly floor, walls, dummy, and sink (Table 2). Similarly, Staph. aureus GTR (farm 20) could be observed on the teat surface and on the floor, but also in the nose and on the hands and clothes of the milkers (Table 2). The corresponding spa type was always t710 or a deletion mutant of it (data not shown).

A clear association was observed between the way of housing cows and Staph. aureus presence on hocks ( $P$ $<0.001)$ : in tiestalls, 64 of 344 cows $(18.6 \%)$ showed a positive result for one or both hocks, whereas in freestalls, 29 of $416(7.0 \%)$ cows tested positive, resulting in an odds ratio of 2.67 (95\% CI: 1.68-4.23).

Flies were rarely observed and captured. Of the 5 flies analyzed, one originating on a case farm was positive for Staph. aureus (GTP, t7013) and all others were negative.

\section{Distribution of Genotypes and spa Types Among Animal Sites}

Table 3 shows a clear association $(P<0.001)$ between location (animal sites) and Staph. aureus genotype. Genotype B was highly associated with the mammary gland: $79 \%$ of the GTB-positive strains found on animal sites were isolated from IMI. In total, 77 of 616 lactating cows (13\%) were GTB-positive. Furthermore, colonization of teat skin by Staph. aureus GTB was observed in 3 of 10 case farms (Table 3). Heifers ( $\mathrm{n}=$ $0)$, calves $(\mathrm{n}=1)$, and other animals $(\mathrm{n}=0)$ were not or very rarely colonized by Staph. aureus GTB.

Genotype C was clearly related to bovine skin: $80 \%$ of the isolates positive for GTC resulted from teat, hock, body surface (perineum), and wounds of cows (Table 3). Furthermore, GTC was the only genotype found on the perineum and in wounds (Table 3). In addition, GTC was isolated from IMI $(\mathrm{n}=10)$ but also from the skin of heifers $(\mathrm{n}=5)$, calves $(\mathrm{n}=2)$, and 1 goat (Table 3).

Other genotypes (GTOG) were generally rarely observed (Table 3); GTA (t529), GTF (t164, t2094, unknown), GTP (t7007), GTR (t012, t710), and GTBS (t571) were found on cow skin (teats, hocks, body surface) and on the body surfaces of heifers and calves. On the bodies of animals other than cattle, Staph. aureus GTF (cat, t164; pigs, t899, t2922, t4358), GTS (pigs, t034), GTU (goat, spa type unknown), and GTZ (goat, spa type unknown) were detected (Table 3). In cow nostrils, particularly GTR (t267, t4318) but also GTA (t529), GTP (t7013), and GTS (t034) were found, 
EPIDEMIOLOGY AND PREVENTION OF INTRAMAMMARY INFECTIONS

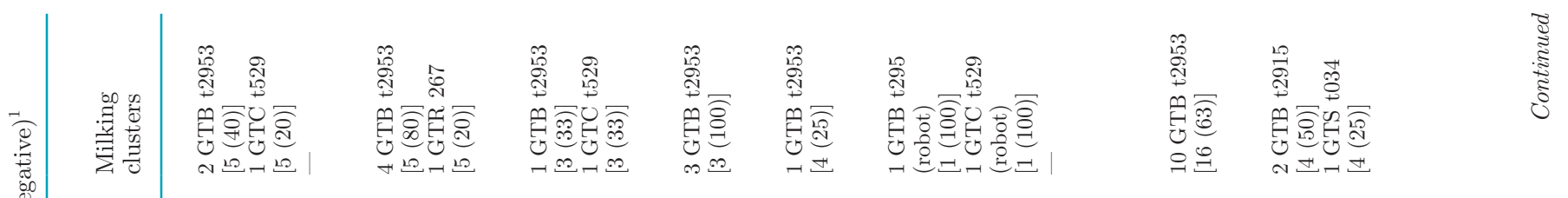
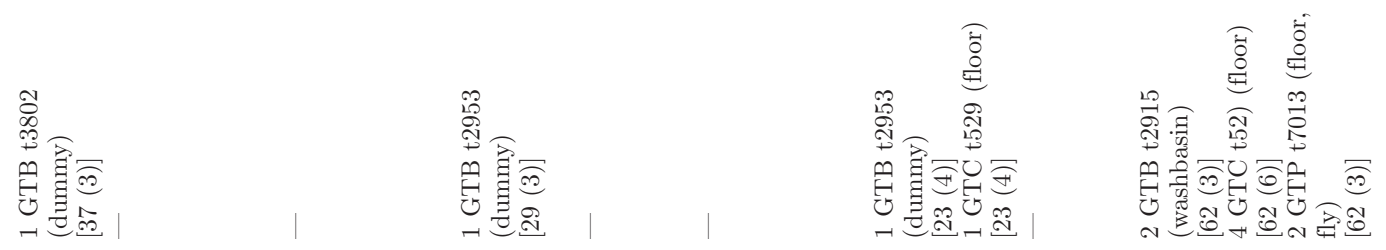

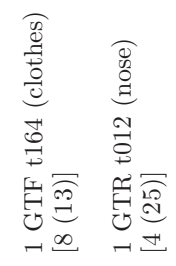

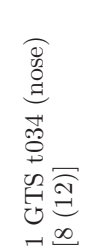

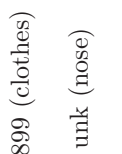

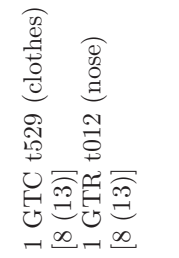

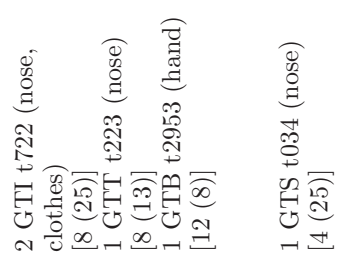

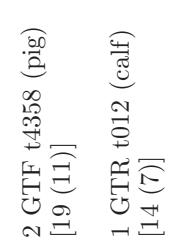

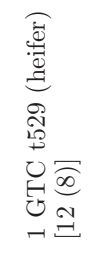

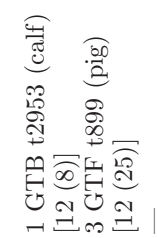

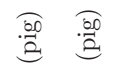

กับ

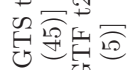

营若

일

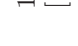

$\begin{array}{lll} & 0 & 0 \\ 0 & 0 \\ 0 & 0 & 0 \\ 0 & 0 \\ 0 & 0 & 0 \\ 0 & 0 & 0 \\ 0 & 0 & 0 \\ -1 & -1 & -1\end{array}$

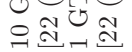

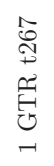

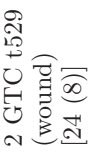

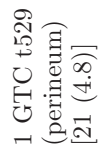
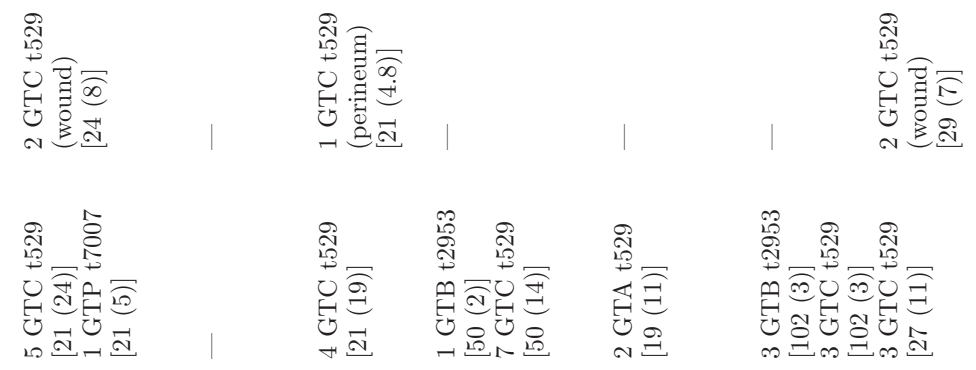

离

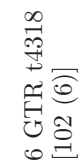

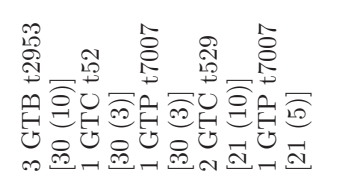

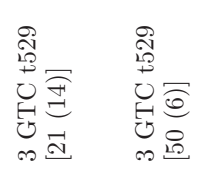

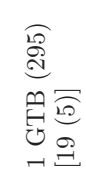

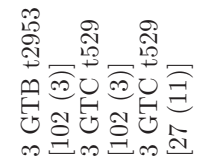

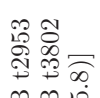

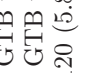

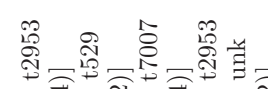

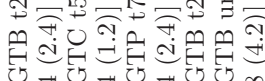

查 语

查

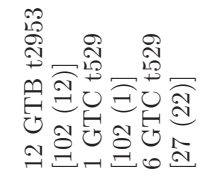


LEUENBERGER ET AL.

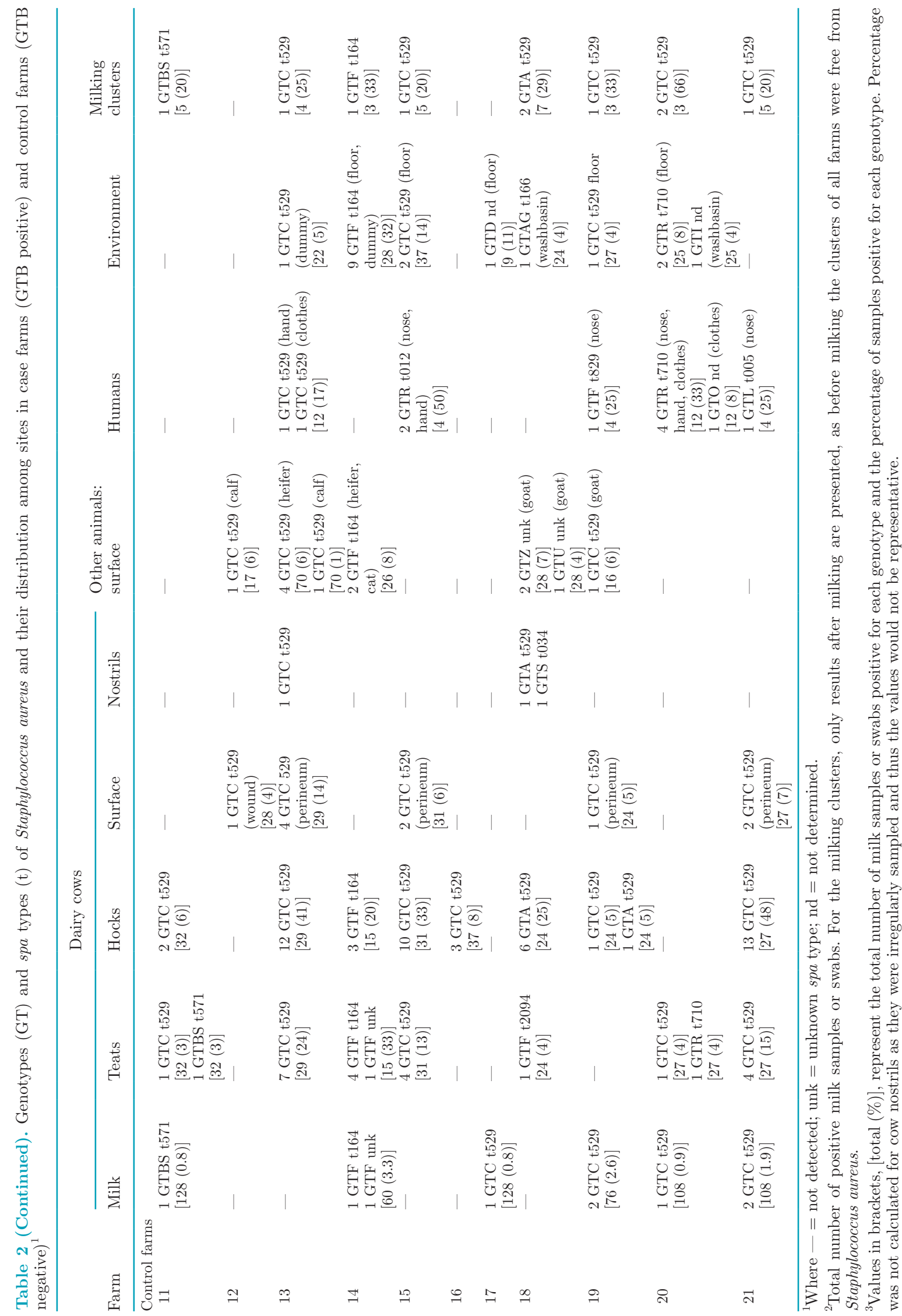


EPIDEMIOLOGY AND PREVENTION OF INTRAMAMMARY INFECTIONS

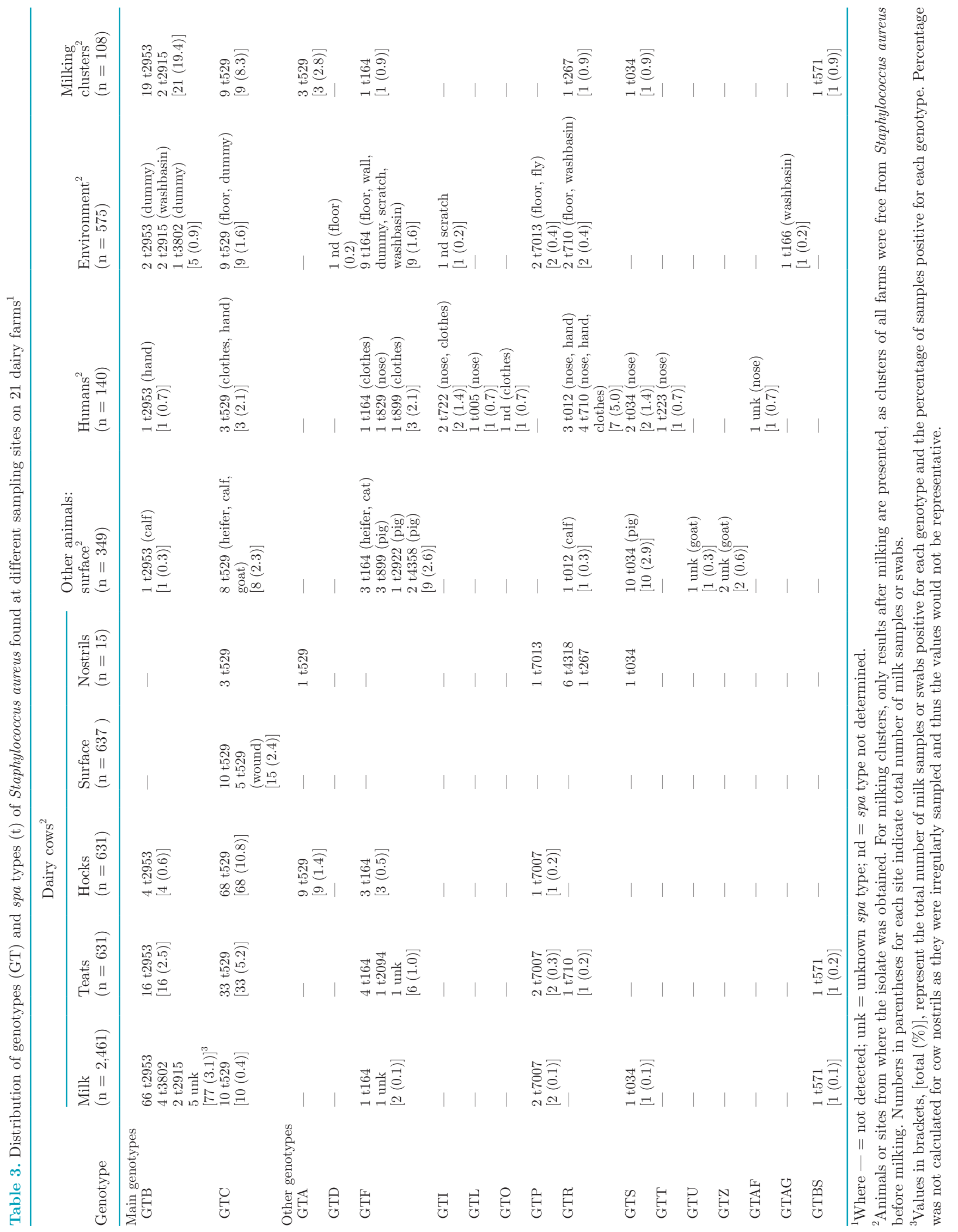


whereas GTF (t164, unknown), GTP (t7007), GTS (t034), and GTBS (t571) were isolated from bovine milk of IMI.

Of the 616 milking cows analyzed in the study, 16 $(2.6 \%)$ were positive for Staph. aureus on the teat surface as well as in milk. On the other hand, 56 cows $(9.1 \%)$ were positive only on the teat surfaces. Taken together, $29 \%$ of cows with positive teat surfaces also had IMI caused by Staph. aureus. This combination was highly dependent on the genotype $(P<0.001)$ : for Staph. aureus GTB, 14 of 15 (93\%; always t2953) cows had GTB detected in milk and on the teat surface; for GTC (always t529), only 1 of 30 cows (3\%) had GTB detected in milk and on the teat surface. Genotype F (spa type unknown), GTP (t7007), and GTBS (t571) were detected in 1 cow each in which IMI and teat carriage were observed together.

\section{Distribution of Genotypes and spa Types Among Milking Clusters and Environmental Sites}

Staphylococcus aureus GTB was frequently detected in milking clusters after milking (Table 3) but, like GTC and GTOG, never before milking. After milking, GTB was particularly observed on the liners (inner surface) of the milking clusters $(\mathrm{n}=21)$. In 19 cases, the milking liners were positive for t2953 and in 2 cases for t2519. Of all 41 milking clusters present on case farms, 21 clusters $(51 \%)$ were positive for GTB. In the environment, GTB was found on dummies $(\mathrm{n}=3 ; 2$ t2953, 1 t3802) and on the surface of washbasins used to wash the milking equipment $(\mathrm{n}=2$; t2915). Genotype $\mathrm{C}$ (always t529) was found in 9 milking clusters after milking but also in the environment, including floor $(\mathrm{n}=8)$ and dummy $(\mathrm{n}=1)$. For GTOG (Table 3), the liners (milking clusters) were occasionally contaminated by GTA (t529), GTF (t164), GTR (t267), GTS (t034), and GTBS (t571). The other genotypes, however, were typically observed in the environment (Table 3); for example, Staph. aureus GTD (spa type not detected), GTF (t164), GTP (t7013), and GTR (t710) were found on floors and walls. Furthermore, GTF (t164) and GTI were detected in the mangers, and GTF (t164), GTR (t710), and GTAG (t166) were found in the washbasin. Finally, one dummy was positive for GTF (t164).

\section{Distribution of Genotypes and spa Types Among Milkers}

A strong association $(P<0.001)$ was observed between genotypes found on humans (nose, hands) and on all other tested sites together (milk samples, teats, hocks, surface nostrils, surfaces of other animals, environment, milking equipment; Table 4$)$. The same strong association was detected for spa types $(P<0.001)$. Indeed, GTL (t005), GTT (t223), and GTAF (unknown) were uniquely and t012 almost exclusively detected on humans (Table 4). In contrast, Staph. aureus GTB $(99.3 \%)$ and GTC (99.4\%) were almost exclusively associated with nonhuman sites (Tables 3 and 4); in fact, GTB and GTC were detected only once on a milker's hand after milking but never before.

Table 4. Overview of Staphylococcus aureus genotypes (GT) and spa types found on humans (milker's nose, hands) or on other sites [cows (milk, teats, hocks, surface, nostrils), the surfaces of other animals, environment, and milking clusters] from 21 dairy farms

\begin{tabular}{|c|c|c|c|c|c|}
\hline \multirow[b]{2}{*}{ Genotype $^{1}$} & \multicolumn{2}{|c|}{ Human sites $(\mathrm{n}=105)^{1}$} & \multicolumn{2}{|r|}{ Other sites $(\mathrm{n}=5,407)^{1}$} & \multirow{2}{*}{$\frac{\text { Total }}{\mathrm{n}}$} \\
\hline & $\mathrm{n}(\%)^{2}$ & spa type ${ }^{3}$ & $\mathrm{n}(\%)$ & spa type & \\
\hline GTB & $1(1.0)$ & t2953 & $133(2.46)$ & t2953, t2915, t3802, unk & 134 \\
\hline GTC & $1(1.0)$ & t529 & $162(3.0)$ & t529 & 163 \\
\hline GTA & - & - & $12(0.22)$ & t529 & 12 \\
\hline GTD & - & - & $1(0.02)$ & nd & 1 \\
\hline GTF & $1(1.0)$ & $\mathrm{t} 829$ & $31(0.57)$ & t164, t899, t4358, unk, t2094, t2922 & 32 \\
\hline GTI & $1(1.0)$ & $\mathrm{t} 722$ & $1(0.02)$ & nd & 2 \\
\hline GTL & $1(1.0)$ & t005 & - & - & 1 \\
\hline GTP & - & - & $8(0.15)$ & t7007, t7013 & 8 \\
\hline GTR & $7(6.7)$ & $\mathrm{t} 710, \mathrm{t} 012$ & $12(0.22)$ & $\mathrm{t} 4318, \mathrm{t} 710, \mathrm{t} 267, \mathrm{t} 012$ & 18 \\
\hline GTS & $2(1.9)$ & t034 & $13(0.24)$ & $\mathrm{t} 034$ & 15 \\
\hline GTT & $1(1.0)$ & $\mathrm{t} 223$ & - & - & 1 \\
\hline GTU & - & - & $1(0.02)$ & unk & 1 \\
\hline GTZ & - & - & $2(0.04)$ & unk & 2 \\
\hline GTAF & $1(1.0)$ & unk & - & - & 1 \\
\hline GTAG & - & - & $1(0.02)$ & t166 & 1 \\
\hline GTBS & - & - & $4(0.07)$ & $\mathrm{t} 571$ & 4 \\
\hline
\end{tabular}

${ }^{1}$ Total number of samples.

${ }^{2} \mathrm{n}=$ number of samples positive per genotype; $\%=$ percentage of samples positive for each genotype.

${ }^{3}$ Where - = not detected; unk = unknown $s p a$ type; nd $=$ not determined. 


\section{Genotypes with a Particular Distribution}

Particular distribution patterns were observed for GTF, GTR, and GTS. Genotype R, together with its spa types t012 and t710, was the most frequently observed genotype in humans (Table 4). It was mainly detected in the nose and on the hands (Table 3 ) before and after milking. If the milker's nose was positive, his hands were normally positive too, with spa types identical to those observed in the nose (farms 15 and 20; Table 3). Genotype $\mathrm{R}$ was also observed in cows, mainly in the nostrils (t267, t4318, but also on a calf (t012), in the environment (t710), and in the milking clusters (t267; Tables 2 and 4). Genotype F (t164) was isolated from various sites such as IMI, teats, hocks, heifers, cat, environment, and milking clusters (farm 14; Table 3). It was also repeatedly isolated from pigs (noses) with the spa types t899, t2922, and t4358. Genotype $\mathrm{S}$ (always t034) was found in the nose of 2 milkers from 2 farms (farms 4 and 10; Table 2). On farm 10, it was further detected in the nose of 10 weaning pigs and once in the milk of IMI (Table 2).

The clothes of milkers were rarely contaminated (Table 3). When clothes were positive for Staph. aureus, GTC (t529), GTF (t164, t899), GTI (t722), GTO (spa type not detected), and GTR (t710) were found.

\section{DISCUSSION}

\section{Staphylococcus aureus GTB}

Staphylococcus aureus GTB was frequently observed in milk of IMI and repeatedly detected on the surfaces of the milking clusters after milking (inner surface of liners). In contrast, GTB was rarely detected in the environment, being found on dummies or on surfaces that were in direct contact with milk (e.g., basins for washing the milking equipment). Milkers very rarely carried Staph. aureus GTB $(\mathrm{n}=1)$; if so, the hands were positive only after milking, never before. Consequently, GTB is highly associated with the mammary gland, and contaminated milk needs to be considered the main source of infection. In fact, knowing that milk of quarters infected with Staph. aureus contains $10^{3}$ to $10^{9}$ staphylococcal cell equivalents (SCE) per $\mathrm{mL}$ of milk (Graber et al., 2007) and that Staph. aureus from other sites need cultural enrichment to be detected, it is obvious that the liners of the milking clusters exert a very high pressure of infection and therefore play a key role in infecting other cows. Indeed, the presence of a few drops of milk containing GTB present on the inner surface of a liner (milk drops are frequently observed after milking a cow) poses a serious threat of infecting the quarter of the next cow milked with the same cup. Our data demonstrate that thorough cleaning of the milking equipment (clusters) twice a day following the manufacturers' protocols, such as using hot water together with alternating acidic and basic cleaning agents, is sufficient to decontaminate the inner side of the liners and claws from Staph. aureus GTB and from all other genotypes.

The presence of Staph. aureus GTB on teat skin as observed in the present study can be explained by contamination during milking, either directly by milk of the infected gland or indirectly by previously contaminated liners or claws. In fact, in 13 of 16 cases where Staph. aureus GTB was detected on the teat skin, the cows also shed GTB in the milk, suggesting the direct route of contamination. In only 3 cases did the contamination arise from contaminated milking equipment (indirect contamination).

Genotype B was rarely observed on hocks and then only on the 2 largest farms of this study. On farm 9 , it was detected on hocks of 3 of 102 cows (Tables 1 and 3). On farm 7, 2.0\% of the cows carried GTB on their hocks (Tables 1 and 3). Obviously, hocks are not a highly associated site for Staph. aureus GTB. The observed presence of GTB on hocks may have resulted from bedding contaminated by leakage of GTB-containing milk of the same cow.

\section{Staphylococcus aureus GTC}

In contrast to GTB, GTC (always t529) was found at all analyzed sites but with a high frequency on normal and injured (wounds) skin of cows, heifers, and calves. In cows, GTC was most frequently observed on hocks, followed by teat skin and perineum (Table 3). In contrast, GTC was rarely detected in milk (Table 3), indicating that it might be a less important mastitis-causing pathogen. The study by Fournier et al. (2008), however, demonstrated that GTC and Staph. aureus GTB were the most prominent genotypes in milk samples sent in to diagnostic laboratories for bacteriological evaluation. These findings demonstrate that IMI caused by Staph. aureus GTC are present on many farms but, on a particular farm, IMI caused by this pathogen is rare.

In humans, GTC was observed only once on a milker's hands after milking (contamination during the milking process), demonstrating that hands play a negligible role in spreading this genotype among cows. In contrast, this genotype was repeatedly isolated from the liners after milking, indicating that contaminated milking clusters play an important role to transfer GTC onto the teats of cows during milking, explaining, at least in part, the high rate of GTC-positive teats. Contaminated milking clusters and the moderate presence of GTC in the environment, however, do not explain the 
fact that Staph. aureus GTC was primarily observed on bovine skin. Indeed, the present data show that skin is a natural habitat of this genotype. Consequently, GTC should be considered an opportunistic colonizer of bovine skin. The presence of GTC on bovine surfaces (teats) is not necessarily linked to the on-farm presence of IMI caused by this genotype: we identified 4 farms on which no cow had IMI caused by GTC, but it was nevertheless found on the skin, including teats and other body sites (see Table 2). This was also true for farms with IMI uniquely caused by Staph. aureus GTB. On those farms, GTC was repeatedly detected on the teat skin and other body sites (Table 2). Furthermore, GTC was found on the skin of heifers and calves although they were all free from mastitis by visual and palpatory inspection.

If the skin is injured, the locally adhered GTC bacteria start multiplying and invading the tissue, resulting in a local infection. These considerations also explain why Staph. aureus GTC was the genotype most isolated from hocks: they are frequently injured (Capurro et al., 2010), allowing local GTC to multiply and infect the skin and the connective tissue below, leading to peritarsitis.

\section{Staphylococcus aureus GTOG}

As the present study demonstrates, Staph. aureus GTA behaved very similarly to GTC. Indeed, like GTC, it was primarily isolated from hocks but also from teat skin, nostrils, and milking equipment. This congruency is not surprising because both genotypes segregated very recently from the same ancestor (Boss et al., 2016) and are both t529-positive, demonstrating their close genomic relationship.

The other genotypes (except GTA) were particularly associated with host transfer. This was true for GTS (farm 10): this genotype was observed in pigs (nose), cow (IMI), and in a human (nose). On-farm transmission of the same clone among different hosts was further confirmed by the fact that all isolates had the spa type t034. The simultaneous presence of t034 isolates in humans, pigs, and cattle on the same farm is new. It is known that t034 strains are mainly isolated from humans, pigs, calves, horses, and poultry (Ballhausen et al., 2017). The present study, however, demonstrates that direct transmission among these hosts is possible. How GTS (t034) was introduced into the present farm is unclear. According to our previous study (Boss et al., 2016), however, all t034-positive strains isolated from animals evolved from a human clone (clonal complex 398) so it is primarily adapted to humans and may be transferred by a human carrier. That this scenario is possible was demonstrated in the present study; on farm 4, GTS (t034) was isolated from a milker's nose but not from any other of the sampled sites. The milker could then transfer the clone via direct contact to other susceptible species such as cattle or pigs. Another way of introduction may be the purchase of infected animals. Once adapted on a farm, the clone with its broad host spectrum could spread from cow to cow by contaminated milking equipment (liners), as observed on farm 10 (Table 3 ) or to pigs by feeding contaminated milk or by a direct contact between humans and pigs.

Genotype F was observed on several farms (Table 2) where it was isolated from cattle, pigs, cat, and humans. Based on the corresponding spa types, however, a direct link among these 4 species was not observed (Tables 3 and 4). Rather, the present study suggests, consistent with Boss et al. (2016), that Staph. aureus GTF (t164) and GTF (t2094) are primarily associated with cattle, milk, IMI, and environment, whereas GTF (t899), GTF (t2922), and GTF (t4358) are related to pigs and $\mathrm{t} 829$ to humans. Interestingly, t899 is a deletion mutant of t4358 (1 repeat within the spa gene is deleted; http:// spa.ridom.de/spaserver). Recently, Chuang and Huang (2015) demonstrated that t899 is frequently present in Asian pigs but also in the noses of Asian pig farmers, indicating a transfer among pigs and humans, a situation that could also occur on Swiss farms. Further studies, however, are required to elucidate this association in more detail and to infer risks for humans in Switzerland and in Europe. This is important because almost all the t899 and t4358 strains present in the Ridom database (http://spa.ridom.de/spaserver) are methicillin resistant, implying a serious threat for humans in the case of a host transfer.

Staphylococcus aureus GTR was the genotype the most frequently isolated from humans, normally from noses and hands of milkers (Tables 3 and 4). There, it was particularly associated with spa types t012 and t710. The spa type t012 is very frequently observed worldwide (http://spa.ridom.de/spaserver) and is associated with human carriage and infection (Grundmann et al., 2010). The spa type t710 is a deletion mutant of t012 (lacking 3 t012-typical repeats), suggesting that these GTR strains are genetically closely related and may, therefore, have some association with humans. Staphylococcus aureus GTR, however, was repeatedly isolated from sites other than from humans (Table 3). Interestingly, some of those isolates were also t012- and t710-positive, indicating that these bacteria were transmitted by the milker. Some genotypes together with their spa types were uniquely observed on humans such as GTL (t005), GTT (t223), and GTAF (unknown), demonstrating a high specificity for this host (Table 4).

Overall, different animals and humans on dairy farms carry their own subtypes of Staph. aureus and are, 
therefore, primarily adapted to different hosts. A few clones, however, are able to cross the species barrier. This is particularly true for Staph. aureus GTS (t034) and GTF (t899, t4358) but also for other subtypes (Sakwinska et al., 2011). From an epidemiological point of view, these clones carry a serious threat for humans and animals, particularly if they are methicillin resistant. Consequently, they need to be controlled in animal and human populations to minimize the threat of methicillin-resistant Staph. aureus (MRSA) infections.

\section{On-Farm Presence of Staphylococcus aureus}

A clear association was observed among genotypes and the tested farms (Table 2). In particular, all GTBpositive strains and their corresponding spa types (mostly t2953) were detected only on the case farms (Table 2). This result is not surprising because farms were assigned to this group if a previous BTM analysis showed a GTB-positive result, whereas farms with a negative result were allocated to the control group. In contrast, Staph. aureus GTOG (various spa types) were observed on both farm types with very similar relative frequencies. A difference was observed for GTC (always t529) because it was isolated slightly more often on control farms than on case farms $(P=0.035)$, suggesting that Staph. aureus GTB may have some negative effect on the distribution of GTC on case farms, a phenomenon previously observed by Michel et al. (2011). Nevertheless, Staph. aureus GTC was by far the most common subtype in cattle (Table 2) and was widely spread (Table 3 ).

As in previous studies (Fournier et al., 2008; Graber et al., 2009), Staph. aureus GTB was repeatedly observed together with GTC or GTOG on the same farm (Table 2, case farms $4,6,7$ ). This observation means that contagious mastitis caused by GTB can be present on the same farm together with the noncontagious form. The present study further shows that on each farm one genotype was generally predominant, a finding also observed by Capurro et al. (2010). On case farms, the predominant genotype was Staph. aureus GTB (mostly t2953), whereas on control farms, it was usually GTC (always t529). Other predominant genotypes (on 1 farm each) were GTA (always t529), GTF (always t164), and GTR (t710 or unknown).

Housing type was clearly related to Staph. aureus carriage on the hocks $(P<0.001)$. Indeed, $18.6 \%$ of the 344 cows housed in tiestalls were positive for one or both hocks, whereas only $7.0 \%$ of 416 cows housed in freestalls were positive. The reason for this phenomenon was that cows were kept on rubber mats covered with a thin layer of sawdust or chopped straw in most tiestalls. This is a well-known situation for causing hock lesions because of friction between the hock and bedding when the cow is rising (Livesey et al., 2002; authors' clinical experience). Friction is even more pronounced when the rubber mats are too short so that the hocks reside on the edge of the mat while cows are lying and moving their legs (authors' clinical experience).

In the present study, Staph. aureus was rarely observed in the environment. These results confirm previous findings by Roberson et al. (1994). In fact, only $2 \%$ of environmental samples were positive. This suggests that environment should be regarded a minimal source for Staph. aureus infections in cattle and other animals. This may also be true for flies, which were infrequently observed on the farms and, therefore, only a few were captured. Out of the 5 flies analyzed, only one was positive for Staph. aureus (GTP, t7013), suggesting that, at least in Switzerland, flies should not be considered a major vector for transmitting Staph. aureus among cows, as described by Anderson et al. (2012).

\section{On-Farm Consequences of the Present Study}

Staphylococcus aureus GTB is contagious and highly associated with the mammary gland. Prevention schemes for contagious mastitis-causing pathogens typically include milking of cows following a strict order, teat dipping, and appropriate milking hygiene (Sears and McCarthy, 2003; Kirchhofer et al., 2011; Sartori et al., 2018). This protocol is no longer adequate for Staph. aureus GTC and GTOG. Based on the present study, these genotypes need to be considered adapted to cattle, being opportunistic colonizers. Important from an epidemiological point of view, Staph. aureus GTC and GTOG cause sporadic and noncontagious IMI (Fournier et al., 2008; Graber et al., 2009). Consequently, the prevention scheme for contagious mastitis-causing pathogens is no longer appropriate for Staph. aureus GTC and GTOG. This is important because Staph. aureus GTC is a frequent mastitis-causing pathogen in Switzerland and in many European countries (Fournier et al., 2008; Cosandey et al., 2016). The sites of predilection of Staph. aureus GTC are skin of hock, teat perineum, and wounds (Table 3). On-farm eradication of Staph aureus GTC and bovine GTOG is difficult because the primary host is cattle. As the hocks are key sites of GTC, GTF, and GTA, a prevention strategy needs to be based on appropriate bedding and housing to avoid injury. These include lying surfaces that are long enough to prevent the hocks being placed on the posterior edge of the surface, and dry, fresh, and deep bedding material such as long straw (not sawdust alone) to cushion the hocks and keep them dry and clean. Furthermore, the milking clusters need to be thoroughly cleaned to prevent, at 
least initially, bacterial spread by contaminated liners during milking of the herd. In spite of these measures, however, sporadic and noncontagious IMI, as caused by Staph. aureus GTC or GTOG, are assumed to be observed regularly as these genotypes are adapted to cattle. Exceptions are expected on farms with a very low Staph. aureus prevalence, as observed on farms 12, 16, and 17 (control farms; Table 2). The reason for this phenomenon, however, is unclear and needs to be further elucidated.

\section{CONCLUSIONS}

We have demonstrated that the epidemiological properties of Staph. aureus on dairy farms clearly depend on the genotype. Staphylococcus aureus GTB is associated with the udder, IMI, and milking clusters, whereas GTC and GTOG are associated with cow and other animal surfaces and the environment. Genotype $\mathrm{R}$ is present on cattle and other animals, especially on mucous membranes (nostrils). Genotype $\mathrm{C}$ is by far the most common subtype in cattle and is widespread on control (GTB-negative) and case (GTB-positive) farms. In addition, each farm had a predominant genotype. On case farms, it was Staph. aureus GTB, whereas on control farms, it was GTC but also GTA and GTF. The genotypes and spa types of Staph. aureus detected in milkers' noses differed from those found in cattle, other animals, milking equipment, and the environment. Exceptions were GTS (t034) and GTF (t899), which crossed the species barrier. In most of the cases, however, the species barrier is maintained because Staph. aureus is adapted to a particular host and even to a particular body site. Because the biological properties differ among genotypes, new guidelines were established to prevent IMI: the classical measures to prevent IMI caused by contagious pathogens still hold for GTB, but not for Staph. aureus GTC and GTA, whose primary habitat is bovine skin. For those genotypes, protection of the skin from minor lesions and wounds, particularly on the hocks, is critical.

\section{ACKNOWLEDGMENTS}

We thank all farmers for their cooperation during our field study. The study was supported by a grant obtained from the Swiss National Science Foundation (SNSF, Berne, Switzerland), project number 310030_143650.

\section{REFERENCES}

Anderson, K. L., R. Lyman, K. Moury, D. Ray, D. W. Watson, and M. T. Correa. 2012. Molecular epidemiology of Staphylococcus aureus mastitis in dairy heifers. J. Dairy Sci. 95:4921-4930.
Ballhausen, B., A. Kriegeskorte, S. van Alen, P. Jung, R. Köck, G. Peters, M. Bischoff, and K. Becker. 2017. The pathogenicity and host adaptation of livestock-associated MRSA CC398. Vet. Microbiol. 200:39-45.

Barkema, H. W., Y. H. Schukken, and R. N. Zadoks. 2006. Invited review: The role of cow, pathogen, and treatment regimen in the therapeutic success of bovine Staphylococcus aureus mastitis. J. Dairy Sci. 89:1877-1895.

Berchtold, B., M. Bodmer, B. H. van den Borne, M. Reist, H. U. Graber, A. Steiner, R. Boss, and F. Wohlfender. 2014. Genotypespecific risk factors for Staphylococcus aureus in Swiss dairy herds with an elevated yield-corrected herd somatic cell count. J. Dairy Sci. 97:4886-4896.

Boss, R., A. Cosandey, M. Luini, K. Artursson, M. Bardiau, F. Breitenwieser, E. Hehenberger, T. Lam, M. Mansfeld, A. Michel, G. Mosslacher, J. Naskova, S. Nelson, O. Podpecan, A. Raemy, E. Ryan, O. Salat, P. Zangerl, A. Steiner, and H. U. Graber. 2016. Bovine Staphylococcus aureus: Subtyping, evolution, and zoonotic transfer. J. Dairy Sci. 99:515-528.

Boss, R., J. Naskova, A. Steiner, and H. U. Graber. 2011. Mastitis diagnostics: Quantitative PCR for Staphylococcus aureus genotype B in bulk tank milk. J. Dairy Sci. 94:128-137.

Capurro, A., A. Aspan, U. H. Ericsson, W. K. Persson, and K. Artursson. 2010. Identification of potential sources of Staphylococcus aureus in herds with mastitis problems. J. Dairy Sci. 93:180-191.

Chuang, Y. Y., and Y. C. Huang. 2015. Livestock-associated methicillin-resistant Staphylococcus aureus in Asia: An emerging issue? Int. J. Antimicrob. Agents 45:334-340.

Cosandey, A., R. Boss, M. Luini, K. Artursson, M. Bardiau, F. Breitenwieser, E. Hehenberger, T. Lam, M. Mansfeld, A. Michel, G. Mosslacher, J. Naskova, S. Nelson, O. Podpecan, A. Raemy, E. Ryan, O. Salat, P. Zangerl, A. Steiner, and H. U. Graber. 2016. Staphylococcus aureus genotype B and other genotypes isolated from cow milk in European countries. J. Dairy Sci. 99:529-540.

Cremonesi, P., F. Pozzi, M. Raschetti, G. Bignoli, E. Capra, H. U. Graber, F. Vezzoli, R. Piccinini, B. Bertasi, S. Biffani, B. Castiglione, and M. Luini. 2015. Genomic characteristics of Staphylococcus aureus strains associated with high within-herd prevalence of intramammary infections in dairy cows. J. Dairy Sci. 98:6828-6838.

Fournier, C., P. Kuhnert, J. Frey, R. Miserez, M. Kirchhofer, T Kaufmann, A. Steiner, and H. U. Graber. 2008. Bovine Staphylococcus aureus: Association of virulence genes, genotypes and clinical outcome. Res. Vet. Sci. 85:439-448.

Graber, H. U., M. G. Casey, J. Naskova, A. Steiner, and W. Schaeren. 2007. Development of a highly sensitive and specific assay to detect Staphylococcus aureus in bovine mastitic milk. J. Dairy Sci. 90:4661-4669.

Graber, H. U., J. Naskova, E. Studer, T. Kaufmann, M. Kirchhofer, M. Brechbuhl, W. Schaeren, A. Steiner, and C. Fournier. 2009. Mastitis-related subtypes of bovine Staphylococcus aureus are characterized by different clinical properties. J. Dairy Sci. 92:1442-1451.

Graber, H. U., S. Pfister, P. Burgener, R. Boss, M. Meylan, and J. Hummerjohann. 2013. Bovine Staphylococcus aureus: Diagnostic properties of specific media. Res. Vet. Sci. 95:38-44.

Grundmann, H., D. M. Aanensen, C. C. van den Wijngaard, B. G. Spratt, D. Harmsen, and A. W. Friedrich. 2010. Geographic distribution of Staphylococcus aureus causing invasive infections in Europe: A molecular-epidemiological analysis. PLoS Med. 7:e1000215.

Halasa, T., K. Huijps, O. Osteras, and H. Hogeveen. 2007. Economic effects of bovine mastitis and mastitis management: A review. Vet. Q. 29:18-31.

Harmsen, D., H. Claus, W. Witte, J. Rothganger, H. Claus, D. Turnwald, and U. Vogel. 2003. Typing of methicillin-resistant Staphylococcus aureus in a university hospital setting by using novel software for spa repeat determination and database management. J. Clin. Microbiol. 41:5442-5448.

Hata, E., K. Katsuda, H. Kobayashi, I. Uchida, K. Tanaka, and M. Eguchi. 2010. Genetic variation among Staphylococcus aureus strains from bovine milk and their relevance to methicillin-resistant isolates from humans. J. Clin. Microbiol. 48:2130-2139. 
Heiniger, D., B. H. P. van den Borne, I. Lechner, A. Tschopp, D. Strabel, A. Steiner, and H. Meier. 2014. Kosten-Nutzen-Analyse einer Intervention zur Verbesserung der Eutergesundheit in Schweizer Milchviehbetrieben. Schweiz. Arch. Tierheilkd. 156:473-481.

Holm, S. 1979. A simple sequentially rejective multiple test procedure. Scand. J. Stat. 6:65-70.

Hummerjohann, J., J. Naskova, A. Baumgartner, and H. U. Graber. 2014. Enterotoxin-producing Staphylococcus aureus genotype B as a major contaminant in Swiss raw milk cheese. J. Dairy Sci. 97:1305-1312.

Kirchhofer, M., T. Kaufmann, M. Guelat-Brechbuhl, A. Michel, C. Syring, and M. Bodmer. 2011. Systematic sanitation of dairy herds with mastitis caused by Staphylococcus aureus. Schweiz. Arch. Tierheilkd. 153:361-368.

Livesey, C. T., C. Marsh, J. A. Metcalf, and R. A. Laven. 2002. Hock injuries in cattle kept in straw yards or cubicles with rubber mats or mattresses. Vet. Rec. 150:677-679.

Lundberg, A., A. K. Nyman, A. Aspan, S. Borjesson, H. E. Unnerstad, and K. P. Waller. 2016. Udder infections with Staphylococcus aureus, Streptococcus dysgalactiae, and Streptococcus uberis at calving in dairy herds with suboptimal udder health. J. Dairy Sci. 99:2102-2117.

Michel, A., C. Syring, A. Steiner, and H. U. Graber. 2011. Intramammary infections with the contagious Staphylococcus aureus genotype B in Swiss dairy cows are associated with low prevalence of coagulase-negative staphylococci and Streptococcus spp. Vet. J. 188:313-317.

NMC (National Mastitis Council). 1999. Laboratory Handbook on Bovine Mastitis. Rev. Ed. National Mastitis Council Inc., Madison, WI
Roberson, J. R., L. K. Fox, D. D. Hancock, J. M. Gay, and T. E. Besser. 1994. Ecology of Staphylococcus aureus isolated from various sites on dairy farms. J. Dairy Sci. 77:3354-3364.

Sakwinska, O., D. Morisset, J. Y. Madec, A. Waldvogel, P. Moreillon, and M. Haenni. 2011. Link between genotype and antimicrobial resistance in bovine mastitis-related Staphylococcus aureus strains, determined by comparing Swiss and French isolates from the Rhone Valley. Appl. Environ. Microbiol. 77:3428-3432.

Sartori, C., R. Boss, M. Bodmer, A. Leuenberger, I. Ivanovic, and H. U. Graber. 2018. Sanitation of Staphylococcus aureus genotype Bpositive dairy herds: A field study. J. Dairy Sci. 101:6897-6914.

Sears, P. M., and K. K. McCarthy. 2003. Management and treatment of staphylococcal mastitis. Vet. Clin. North Am. Food Anim. Pract. 19:171-185.

Syring, C., R. Boss, M. Reist, M. Bodmer, J. Hummerjohann, P. Gehrig, and H. U. Graber. 2012. Bovine mastitis: The diagnostic properties of a PCR-based assay to monitor the Staphylococcus aureus genotype B status of a herd, using bulk tank milk. J. Dairy Sci. 95:3674-3682.

van den Borne, B. H. P., H. U. Graber, V. Voelk, C. Sartori, A. Steiner, M. C. Haerdi-Landerer, and M. Bodmer. 2017. A longitudinal study on transmission of Staphylococcus aureus genotype B in Swiss communal dairy herds. Prev. Vet. Med. 136:65-68.

Voelk, V., H. U. Graber, B. H. van den Borne, C. Sartori, A. Steiner, M. Bodmer, and M. C. Haerdi-Landerer. 2014. A longitudinal study investigating the prevalence of Staphylococcus aureus genotype B in seasonally communal dairy herds. J. Dairy Sci. 97:4184-4192. 